\title{
Comprehensive Evaluation of Cultivated Land Resources in China Based on Three Dimensions: Quantity, Quality and Ecology Danger
}

\author{
Renyi Yang ${ }^{1}$, Zisheng Yang ${ }^{1, *}$, and Fenglian Liu ${ }^{1}$ \\ ${ }^{1}$ Institute of Land \& Resources and Sustainable Development, Yunnan University of Finance and Economics, Kunming 650221, China
}

\begin{abstract}
Based on TOPSIS-Grey Relational Analysis Method, the three dimensions of cultivated land quantity, quality and ecological danger are organically integrated to build a comprehensive evaluation indicator system of practical and national cultivated land resources and quantitative calculation method by taking the province-level administrative region as the evaluation unit. The index of cultivated land quantity, quality, and ecological danger and the comprehensive index of cultivated land resources are calculated quantitatively in 31 province-level administrative regions of China. The comprehensive endowment and superiority of cultivated land resources in each province are also analysed systematically. The results show that there are 10 provinces (municipalities directly under the Central Government and autonomous regions) classified as "high superiority" provinces in terms of cultivated land resources. There are 9 provinces classified as "relatively high superiority" provinces. The dominant types of cultivated land resources in China can be classified into six types: superiority type of quantity, superiority type of quantity and ecology, superiority type of quality and ecology, superiority type of ecology, comprehensive superiority type, and unclear superiority type. Most provinces have a certain "single superiority", "double superiority", or "comprehensive superiority".
\end{abstract}

\section{Introduction}

The ancient Chinese sayings "all things are born in the soil" and "where there is soil, there is grain", which profoundly reveal the close relationship between cultivated land resources and food security. The quantity, quality and utilization of cultivated land resources in a country and region fundamentally determine the effective food supply and food security plan [1]. Internationally, the United States, the United Kingdom, Germany, France, the Netherlands and other countries have early started the research on the investigation, evaluation and protection of land resources, including cultivated land resources. Among them, the most representative is the land capability classification system issued by the United States Department of agriculture [2] (1961) for servicing land protection, land suitability evaluation system formulated by FAO [3] (1976) and modern information system technology was used to predict crop yield in large regions by FAO [4] and dumanski [5], which are widely used in land resource investigation, land suitability evaluation, cultivated land quality classifying and grading in the world. China is a country with a large population and a small amount of cultivated land. The per capita cultivated land area is less than $1 / 2$ of the world's per capita level. For a long time, China has been feeding $20 \% \sim 22 \%$ of the world's population only by using about $7 \% \sim 10 \%$ of the world's cultivated land. Therefore, the research on the quantity change, quality evaluation and ecological security condition of cultivated land resources has been highly paid attention by governments at all levels and academic circles. In recent decades, research results have been emerging constantly. In terms of cultivated land quantity change, Bi Yuyun et al. [6] (2000) and Feng Zhiming et al. [7] (2005) have analyzed the dynamic changes of cultivated land resources of China since 1949. Yang Zisheng [8] (2008) has discussed the necessity of adhering to the cultivated land red line of 18 million mu on the basis of analyzing cultivated land area change of China from 1996 to 2006. Cao Xue et al. [9] (2014) have reconstructed data sets of cultivated land in China in recent 300 years and have analyzed changes of cultivated land of China. Tan Yongzhong et al. [10] (2017) have analyzed the spatial pattern of cultivated land area change of China before and after the second national land survey. GAO et al. [11] (2019) have analyzed the change of cultivated land spatial and temporal characteristics of China from 1990 to 2015 based on the geomorphic zoning. LAI et al. [12] (2020) analyzed the change of cultivated land use of China since the reform and opening up period. In addition, there were plenty of the studies of cultivated land quantity change. Wu et al. [13] (2017) studied cultivated land protection policy of China based on the dynamic balance of total cultivated land and basic cultivated land zoning. Deng et al. [14] (2015), Li et al. [15] (2015) and Cui Xufeng [16] (2018) studied cultivated

\footnotetext{
* Corresponding author: yangzisheng@126.com
} 
land non-agriculturalization of China, etc. From the perspective of national cultivated land survey, the first national detailed survey of land resources [17] and the second national land survey [18] were completed in 1996 and 2009 respectively. The national cultivated land and other types of land area and vector data were summarized. At present, the third national land survey will nearly complete [19]. In the aspect of cultivated land quality evaluation, the most representative was 1:1 million land resources map of China compiled in 1986, which was the first time to assess the suitability grades of land in China, including the grades of arable land. Since 1999, the Ministry of land and resources (renamed the Ministry of natural resources now) has deployed and carried out the nationwide cultivated land quality grading survey, and completed national cultivated land quality grade achievements based on the first detailed survey of land resources in December 2009. Since 2011, based on the results of the second land survey and its change survey results, the Ministry of land and resources has conducted a supplementary survey on the national cultivated land quality grade achievements. Since 2014 , it has carried out annual updating evaluation and monitoring of cultivated land quality grade. In December 2017, the Ministry of land and resources published the 2016 national cultivated land quality grade update evaluation results [21-22], which divided the cultivated land into 15 grades. At the same time, since 2002, the Ministry of agriculture has also launched a nationwide capability investigation and quality evaluation of cultivated land, and issued the national Bulletin of cultivated land quality grade [23] in December 2014. In May 2020, the Ministry of agriculture and rural areas issued the bulletin on the national cultivated land quality grade in 2019 [24], which divided the cultivated land into 10 grades. In addition, Wang Hongbo et al. [25] (2011) have analyzed the differentiation characteristics of cultivated land in China and its impact on cultivated land protection. Zou Jinlang et al. [26] (2015) analyzed the structural characteristics of cultivated land output of China. Xu et al. [27] (2017), Wang et al. [28] (2019), Gao Chan et al. [29] (2020) have analyzed and evaluated cultivated land of productivity in China. In terms of cultivated land ecological evaluation, it mainly involved cultivated land ecological danger [30] (including cultivated land pollution [31-33], cultivated land soil erosion [34], cultivated land natural disasters [35-38], etc.), cultivated land ecological security [39-41] and cultivated land system security evaluation [42], and cultivated land restoration in ecological damaged areas [43], etc.

The practice of cultivated land quantity survey and evaluation, cultivated land quality evaluation and cultivated land ecological evaluation has greatly promoted the development of cultivated land resources evaluation theory and method, and provided an important basis for a country to formulate cultivated land utilization and remediation planning, cultivated land protection policy, and national land space management decisionmaking. However, on the whole, the quantitative index, quality index and ecological index of cultivated land evaluation at present basically belong to "single item" index. It is urgent to establish a comprehensive evaluation indicator system and quantitative measurement method of cultivated land resources, which can integrate quantitative evaluation, quality evaluation and ecological danger evaluation, so as to evaluate, measure and compare differences of comprehensive endowment and superiority and inferiority of cultivated land resources among all provinces (municipality directly under the Central Government, Autonomous Region, hereinafter referred to as the province) to formulate the strategic decisionmaking and scientific planning of comprehensive utilization, protection and remediation of cultivated land resources at the national level. Therefore, this paper plans to take the province-level administrative region as the analysis and evaluation unit, organically integrate the three dimensions of cultivated land: quantity evaluation, quality evaluation and ecological danger evaluation, and build a set of practical and feasible comprehensive evaluation indicator system and quantitative calculation method of cultivated land resources, so as to provide technical support for scientific analysis of comprehensive endowment and development and utilization superiority of cultivated land resources in all provinces of China.

\section{Research Method}

\subsection{Research Ideas}

The comprehensive evaluation of cultivated land resources in this paper takes the province-level administrative region as the evaluation unit, organically integrates the quantity of cultivated land resources, the quality of cultivated land resources and the ecological danger of cultivated land utilization, and comprehensively evaluates the comprehensive endowment and superiority and inferiority of provincial cultivated land resources. At the national level, the evaluation research results are not only the important basis for formulating the planning of cultivated land utilization, protection and remediation, but also the important basis for land spatial management decision-making and management effect evaluation. Therefore, it is necessary to study and establish a set of specific, feasible and practical comprehensive evaluation indicator system of cultivated land resources. In the past, most researchers used to divide the indicator system into three levels (i.e., target level, criterion level and indicator level) before hierarchical processing. The commonly used evaluation methods mainly include analytic hierarchy process (AHP), entropy weight method, comprehensive analysis method, etc., which are relatively mature in application, but each has its superiority and inferiority [44]. Based on the development of similar evaluation research field in recent years, this paper combines TOPSIS (approximate ideal solution sorting method) and grey correlation analysis method, and calculates the quantity index, quality index and ecological danger index of cultivated land resources in each province on the basis of constructing a series of indicator systems of cultivated land resources quantity, quality and ecological danger. Then the three indexes are organically integrated to calculate the province-level comprehensive evaluation index of cultivated land resources, so as to get the overall 
evaluation and cognition of the cultivated land utilization system of each province, aiming at comprehensively measuring and comparing the comprehensive endowment and superiority and inferiority of the cultivated land resources in each province.

\subsection{Comprehensive Evaluation Method of Cultivated Land Resources Based On TOPSIS- Grey Correlation Analysis Method}

Technique for Order Preference by Similarity to an Ideal Solution is a common decision-making technique for multi-objective decision-making analysis of finite schemes in systems engineering [45]. This method judges the superiority and inferiority of a system by calculating the weighted Euclidean distance between the system and the positive and negative ideal solutions. It has a concise thought and convenient calculation. In recent years, it has also been used in the comprehensive evaluation of multiple indexes. However, there are still some problems in the applications of this method to the comprehensive evaluation. It reflects the relative position relationship of the data curve, and cannot reflect the dynamic change of the system, so it is difficult to obtain a reasonable evaluation result [46]. Grey relational analysis method is a branch of grey system theory. One of the characteristics different from traditional statistical methods is that it can use relatively small amount of data to evaluate the quantitative and qualitative relationship between factors and variables [47], and has the superiorities of low sample size, simple calculation and concise regularity [48]. The combination of TOPSIS method and grey correlation analysis method is used to improve the TOPSIS method, which can more accurately express the degree of fit between alternative schemes and ideal schemes [49], so as to improve the accuracy of the evaluation result [50]. In this paper, the comprehensive evaluation method of cultivated land resources based on TOPSIS-Grey Relational Analysis Method is as follows:

\section{Constructing Weighted Decision Matrix $\mathbf{R}$.}

$$
\boldsymbol{R}=\left[R_{i j}\right]_{m \times n}=\left[I_{i j} \times W_{j}\right]_{m \times n}
$$

In formula (1), $m$ is the total number of province-level administrative regions; $n$ is the total number of indicators; $I=1,2, \ldots, m$ is the province-level administrative region; $J=1,2, \ldots, n$ is the indicator; $I_{i j}$ is the attribute value of indicator $J$ of province $I$ after dimensionless treatment; $W_{J}$ is the indicator weight determined by entropy weight method.

The specific method of calculating indicator weight by entropy weight method is as follows:

(1) The indicators with positive and negative attributes were dimensionless respectively. The specific method is shown below.

(2) Calculate the information entropy of each indicator.

$$
E_{j}=-\frac{\sum_{i=1}^{m} P_{i j} \ln \left(P_{i j}\right)}{\ln (m)}, \quad P_{i j}=\frac{I_{i j}}{\sum_{i=1}^{m} I_{i j}}
$$

In formula (1), if $P_{i j}=0$, then we will definition $P_{i j} \ln \left(P_{i j}\right)=0$.
(3) According to the information entropy $\left(E_{1}, E_{2}, \ldots\right.$, $\left.E_{\mathrm{n}}\right)$, The weight of each indicator is calculated as:

$$
w_{j}=\frac{1-E_{j}}{n-\sum_{j=1}^{n} E_{j}}
$$

2. Calculating the Euclidean Distance of Positive and Negative Ideal Solutions $\left(D^{+}, D_{i}^{-}\right)$

$$
D_{i}^{+}=\sqrt{\sum_{j=1}^{n}\left(R_{i j}-Q_{j}^{+}\right)^{2}}, D_{i}^{-}=\sqrt{\sum_{j=1}^{n}\left(R_{i j}-Q_{j}^{-}\right)^{2}}
$$

In formula (4),

$$
\left\{\begin{array}{l}
Q_{j}^{+}=\max \left(R_{i j}\right), i=1,2, \cdots, m \\
Q_{j}^{-}=\min \left(R_{i j}\right), i=1,2, \cdots, m
\end{array}\right.
$$

indicate positive and negative ideal solutions of each provincelevel administrative region respectively.

3. Calculating the Grey Correlation Degree of Positive and Negative Ideal Solutions $\left(\mathrm{P}_{i}^{+}, \boldsymbol{P}_{i}^{-}\right)$

The grey correlation degree of positive and negative ideal solutions of province $I$ can be expressed as follows:

$$
P_{i}^{+}=\frac{\sum_{j=1}^{n} \rho_{i j}^{+}}{n}, P_{i}^{-}=\frac{\sum_{j=1}^{n} \rho_{i j}^{-}}{n}
$$

We assume that $\mu \in[0,1]$ is the resolution coefficient (generally taken as 0.5 ), Then the grey correlation coefficient in formula (6) can be expressed as follows:

$$
\begin{gathered}
\rho_{i j}^{+}=\frac{\min _{1 \leq \mathrm{j} \leq \mathrm{n}} \min _{1 \leq \mathrm{i} i \mathrm{~m}}\left|Q_{j}^{+}-R_{i j}\right|+\mu \max _{1 \leq \mathrm{j} \leq \mathrm{n}} \max _{1 \leq \mathrm{i} \leq \mathrm{m}}\left|Q_{j}^{+}-R_{i j}\right|}{\left|Q_{j}^{+}-R_{i j}\right|+\mu \max _{1 \leq \mathrm{j} \leq \mathrm{n}} \max _{1 \leq \mathrm{i} \leq \mathrm{m}}\left|Q_{j}^{+}-R_{i j}\right|}, \\
\rho_{i j}^{-}=\frac{\min _{1 \leq \mathrm{j} \leq \mathrm{n}} \min _{1 \leq \mathrm{i} \leq \mathrm{m}}\left|Q_{j}^{-}-R_{i j}\right|+\mu \max _{1 \leq \mathrm{j} \leq \mathrm{n}} \max _{1 \leq \mathrm{i} \leq \mathrm{m}}\left|Q_{j}^{-}-R_{i j}\right|}{\left|Q_{j}^{-}-R_{i j}\right|+\mu \max _{1 \leq \mathrm{j} \leq \mathrm{n}} \max _{1 \leq \mathrm{i} \leq \mathrm{m}}\left|Q_{j}^{-}-R_{i j}\right|}
\end{gathered}
$$

4. Calculate Closeness Degree $\left(C_{i}^{+}\right)$

$$
C_{i}^{+}=\frac{e_{1} d_{i}^{-}+e_{2} p_{i}^{+}}{e_{1}\left(d_{i}^{-}+d_{i}^{+}\right)+e_{2}\left(p_{i}^{-}+p_{i}^{+}\right)}
$$

In formula (7), $d_{i}^{-}, d_{i}^{+}, p_{i}^{-}, p_{i}^{+}$respectively indicate dimensionless values of $D_{i}^{-}, D_{i}^{+}, P_{i}^{-}, P_{i}^{+} . e_{1}, e_{2}$ is the degree of decision preference. Normally, $e_{1}+e_{2}=1$. For the sake of simplification, we can define $e_{1}=e_{2}=0.5$. The specific dimensionless method is as follows:

$$
\begin{cases}d_{i}^{-}=D_{i}^{-} / \max \left(D_{i}^{-}\right), & d_{i}^{+}=D_{i}^{+} / \max \left(D_{i}^{+}\right) \\ p_{i}^{-}=P_{i}^{-} / \max \left(P_{i}^{-}\right), & p_{i}^{+}=P_{i}^{+} / \max \left(P_{i}^{+}\right)\end{cases}
$$

5. Calculating the Index of Farmland Quantity, Index of Farmland Quality and Index of Ecological Danger

According to the final calculated closeness degree, the quantity, quality and ecological danger of cultivated land in each province-level administrative region of China will be evaluated. The value range of closeness degree is $[0,1]$. The higher value of closeness degree is, the richer the cultivated land resource endowment will have, the better quality of cultivated land or the lower ecological danger degree will have and vice versa. According to it, the index of farmland quantity $\left(I_{F Q 1}\right)$, index of farmland quality $\left(I_{F Q 2}\right)$ and index of ecological danger $\left(I_{E D}\right)$ can be calculated by using the closeness degree to represent the cultivated land conditions of each province-level administrative region in China. 


$$
\left\{\begin{array}{l}
I_{F Q 1}=F Q_{1} C_{i}^{+} \times 100 \\
I_{F Q 2}=F Q_{2} C_{i}^{+} \times 100 \\
I_{E D}=E D C_{i}^{+} \times 100
\end{array}\right.
$$

In formula (9), $F Q_{1} C_{i}^{+}, \quad F Q_{2} C_{i}^{+}$and $E D C_{i}^{+}$ respectively indicate the closeness degree of comprehensive quantity, quality and ecological danger index of farmland. The reason why the formula is multiplied by 100 is to ensure that the value range of the three indexes is $[0,100]$.

6. Calculating the Comprehensive Index of Farmland Resources

Comprehensive Index of Farmland Resources $\left(C I_{F R}\right)$ is a quantitative evaluation index for the comprehensive condition of cultivated land resources. It is an organic synthesis and integration of $I_{F Q 1}, I_{F Q 2}$ and $I_{E D}$.

The total output of cultivated land is affected by a lot of conditions. Among them, the quantity, quality and ecological danger of cultivated land are very important factors. However, these factors are not isolated, they are an organic whole which is related to each other. It is similar to the "barrel law". In this whole, if a certain index is low, it will critically affect the level of the whole. According to this, we can refer to the calculation formula of human development index (HDI), and use the geometric average of $I_{F Q 1}, I_{F Q 2}$ and $I_{E D}$ to reflect the comprehensive endowment conditions of cultivated land resources. The calculation formula of $C I_{F R}$ is set as follows:

$$
C I_{F R}=\sqrt[3]{I_{F Q 1} \cdot I_{F Q 2} \cdot I_{E D}}=I_{F Q 1} \frac{1}{3} \cdot I_{F Q 2} \frac{1}{3} \cdot I_{E D} \frac{1}{3}
$$

The comprehensive endowment of cultivated land resources in a province is affected by the quantity, quality and ecological danger of cultivated land, but the degree of influence will be quite different. However, formula (10) takes the product of the $1 / 3$ power of each index as the comprehensive endowment index of cultivated land resources. In other words, its weight setting value is the same, which is obviously unreasonable. So the comprehensive endowment of cultivated land resources calculated by formula (10) may deviate from the actual situation. Therefore, formula (10) needs to be improved properly. The improved calculation method of comprehensive index of farmland resources is as follows:

$$
C I_{F R}=I_{F Q 1}{ }^{\alpha} \cdot I_{F Q 2}{ }^{\beta} \cdot I_{E D}^{\gamma}
$$

In formula (11), $\alpha 、 \beta 、 \gamma$ respectively indicate weight value of $I_{F Q 1}, I_{F Q 2}$ and $I_{E D}$. They satisfy the following relations: $\alpha+\beta+\gamma=1$. Because $I_{F Q 1}, I_{F Q 2}$ and $I_{E D}$ belong to three different categories and different dimensions of comprehensive index, and entropy weight method determines the index weight according to the information provided by the observation value of each index, ignoring the importance of the index itself. Therefore, Delphi method (also called expert consultation method) is properly adopted here. In October 2020, 18 experts and scholars were organized to assign the weights of the above-mentioned $I_{F Q 1}, I_{F Q 2}$ and $I_{E D}$. After treatment, the weight values of the three indexes were obtained: $\alpha=0.58$, $\beta=0.24, \quad \gamma=0.18$.
The higher value of $C I_{F R}$ is, The better comprehensive endowment of cultivated land resources will have and the more benefit of superiority and conditions of cultivated land utilization will show.

\subsection{Construction of Evaluation Indicator System}

As a form of policy guidance, the evaluation indicator system should not only reflect the leading idea of coordinated development of many aspects with the owner of cultivated land, but also make each evaluation indicator the most sensitive, convenient, and abundant leading indicator among the numerous indicators reflecting regional cultivated land use system, so that the evaluation indicator system can best describe the state change trend of regional cultivated land use In view of this, the following principles should be followed in the construction of comprehensive evaluation indicator system of cultivated land resources: (1) To reflect the superiority and inferiority of regional comprehensive endowment and development and utilisation of cultivated land resources. (2) To embody the practicability and pertinence of "province region" — a large regional scale feature. (3) Strengthen and pay attention to the scientific nature, operability, and relative completeness of indicator selection. (4) Fully consider the availability, sensitivity, and quantifiable of the basic data enshrined in such indicators.

A cultivated land use system is a complex ecological economic and social composite system, which involves a series of related factors and several coordinated development conditions. It endows the comprehensive evaluation of cultivated land resources with characteristics of system complexity, multi-factor relevance, multiple realisation mechanisms, regional differences and particularities, etc. Therefore, the construction of provincial comprehensive evaluation indicator system of cultivated land resources should focus on the characteristics of provincial ecological environment and cultivated land utilisation, taking the comprehensive evaluation of quantity, quality, and ecological danger of cultivated land resources as its core, while highlighting the impact of comprehensive endowment conditions of cultivated land resources on ecological, economic, and social progress. In view of this, in setting the evaluation indicators, we should select typical, sensitive indicators which are independent and can reflect the characteristics of various aspects on the basis of fully understanding the structure, function, characteristics, and utilisation objectives of provincial land use systems to establish an indicator system framework of comprehensive evaluation of cultivated land resources and we divided the comprehensive evaluation indicator system of cultivated land resources into three levels: indicator category, evaluation indicator, and element indicator. We constructed a concise, practical, and feasible provincial cultivated land resource evaluation indicator system (Table 1). 
Table1. Comprehensive evaluation indicator system and data acquisition modes of cultivated land resources at provincial level.

\begin{tabular}{|c|c|c|c|c|c|c|}
\hline \multirow{3}{*}{$\begin{array}{l}\text { Evaluation } \\
\text { indicator } \\
\text { categories }\end{array}$} & \multicolumn{4}{|c|}{ Evaluation indicators } & \multirow{3}{*}{ Element indicator } & \multirow{3}{*}{ Data source } \\
\hline & \multicolumn{2}{|c|}{ First level } & \multicolumn{2}{|c|}{ Second level } & & \\
\hline & Indicator & Weight & Indicator & Weight & & \\
\hline \multirow{4}{*}{$\begin{array}{l}\text { Indicator } \\
\text { categories of } \\
\text { cultivated } \\
\text { land quantity }\end{array}$} & \multirow[b]{2}{*}{$\begin{array}{l}\text { Index of } \\
\text { Total Area }\end{array}$} & \multirow[b]{2}{*}{0.5113} & \multirow[b]{2}{*}{ - } & \multirow[b]{2}{*}{ - } & Total area of each province & \multirow{2}{*}{$\begin{array}{c}\text { Statistical Yearbook of } \\
\text { Land and Resources of } \\
\text { China, China Statistical } \\
\text { Yearbook }\end{array}$} \\
\hline & & & & & Total area of China & \\
\hline & \multirow{2}{*}{$\begin{array}{l}\text { Index of } \\
\text { Area Per } \\
\text { Capita }\end{array}$} & \multirow{2}{*}{0.4887} & \multirow{2}{*}{ - } & \multirow{2}{*}{ - } & $\begin{array}{c}\text { Total population of each } \\
\text { province }\end{array}$ & \multirow{2}{*}{$\begin{array}{c}\text { Statistical Yearbook of } \\
\text { Land and Resources of } \\
\text { China, China Statistical } \\
\text { Yearbook }\end{array}$} \\
\hline & & & & & $\begin{array}{c}\text { Total cultivated land area of } \\
\text { each province }\end{array}$ & \\
\hline \multirow{4}{*}{$\begin{array}{l}\text { Indicator } \\
\text { categories of } \\
\text { cultivated } \\
\text { land quality }\end{array}$} & \multirow{2}{*}{$\begin{array}{l}\text { Index of } \\
\text { Quality } \\
\text { Grade }\end{array}$} & \multirow{2}{*}{0.4423} & \multirow{2}{*}{ - } & \multirow{2}{*}{ - } & $\begin{array}{c}\text { Cultivated land quality grade } \\
\text { of each province }\end{array}$ & \multirow{2}{*}{$\begin{array}{c}\text { Special Investigation } \\
\text { and Evaluation of the } \\
\text { Ministry of Land and } \\
\text { Resources }\end{array}$} \\
\hline & & & & & $\begin{array}{l}\text { Cultivated land quality grade } \\
\text { of China }\end{array}$ & \\
\hline & \multirow{2}{*}{$\begin{array}{c}\text { Index of } \\
\text { Annual Grain } \\
\text { Yield Per } \\
\text { Unit Area of } \\
\text { cultivated } \\
\text { land } \\
\end{array}$} & \multirow{2}{*}{0.5577} & \multirow{2}{*}{ - } & \multirow{2}{*}{ - } & $\begin{array}{l}\text { Annual grain yield per unit } \\
\text { area of cultivated land of } \\
\text { each province }\end{array}$ & \multirow{2}{*}{$\begin{array}{l}\text { China Statistical } \\
\text { Yearbook }\end{array}$} \\
\hline & & & & & $\begin{array}{l}\text { Annual grain yield per unit } \\
\text { area of cultivated land of } \\
\text { China }\end{array}$ & \\
\hline \multirow{7}{*}{$\begin{array}{l}\text { Indicator } \\
\text { categories of } \\
\text { cultivated } \\
\text { land } \\
\text { ecological } \\
\text { danger }\end{array}$} & \multirow{2}{*}{$\begin{array}{l}\text { Index of Soil } \\
\text { Loss }\end{array}$} & \multirow[b]{2}{*}{0.5492} & $\begin{array}{l}\text { Index of Soil } \\
\text { Loss Area }\end{array}$ & 0.4204 & $\begin{array}{c}\text { Area and proportion of Soil } \\
\text { Loss }\end{array}$ & \multirow{2}{*}{$\begin{array}{c}\text { Special Investigation } \\
\text { and Monitoring of Soil } \\
\text { and Water Loss of the } \\
\text { Ministry of Water } \\
\text { Resources }\end{array}$} \\
\hline & & & $\begin{array}{l}\text { Index of Soil } \\
\text { Loss Intensity }\end{array}$ & 0.5796 & $\begin{array}{l}\text { Soil and water loss area of } \\
\text { each intensity level }\end{array}$ & \\
\hline & & & $\begin{array}{l}\text { Index of } \\
\text { Disaster- }\end{array}$ & 06771 & $\begin{array}{c}\text { Area of disaster-affected } \\
\text { Crops }\end{array}$ & China Statistical \\
\hline & & & $\begin{array}{c}\text { affected Crops } \\
\text { Area } \\
\end{array}$ & & Total sown area of crops & Yearbook \\
\hline & $\begin{array}{l}\text { Index of } \\
\text { Natural } \\
\text { Disaster }\end{array}$ & 0.4508 & $\begin{array}{l}\text { Index of } \\
\text { Grain }\end{array}$ & 02720 & $\begin{array}{c}\text { Area of disaster-affected } \\
\text { crops and disaster-destroyed } \\
\text { crops } \\
\end{array}$ & China Statistical \\
\hline & & & Reduced by & 0.3229 & $\begin{array}{c}\text { Total sown area and grain } \\
\text { crop area }\end{array}$ & Yearbook \\
\hline & & & & & Total output of grain & \\
\hline
\end{tabular}

As the first level of comprehensive evaluation index system, indicator category depends on the basic content of evaluation. As mentioned above, the basic content of comprehensive evaluation of cultivated land resources includes three parts: first, the quantity of cultivated land resource (reflecting the status of cultivated land in the aspect of "quantity"), the second is the quality of cultivated land (reflecting the status of cultivated land in the aspect of "quality"), and the third is the ecological danger to cultivated land (reflecting the status of cultivated land in the aspect of "environment"). These three constitute a whole evaluation system of cultivated land resources. The formation, cultivation, and development of sustainable utilisation capacity of cultivated land in any region are the result of the comprehensive action of all parts of the whole system, rather than the any single part and its content. According to this, the comprehensive evaluation index of cultivated land resources can be divided into three categories: quantity, quality, and ecological danger indicator category of cultivated land.

The evaluation indicator is a quantitative analysis index under the indicator category, selected to reflect each evaluation content of cultivated land use system. Generally, the basic content of each evaluation needs several indices to be expressed specifically and quantitatively, so each indicator category is often composed of specific evaluation indicators with different numbers. In view of the complexity of cultivated land ecological danger evaluation indicators, it can be further divided into two levels of indicators (Table 1). Each evaluation indicator is specifically expressed by several element indicators.

Element indicator is the basic indicator used to represent the evaluation index. It is the lowest level in the whole evaluation index system and belongs to the smallest unit [51]. It is a specific measure used to evaluate the regional cultivated land resources. According to the actual situation of the province, we should highlight the key 
points and select measurable, comparable, and available quantitative indicators or groups of indicators to express directly the quantitative performance, intensity performance, and speed performance of evaluation indicators.

\subsection{The Method of Dimensionless Index}

In the general sense of cultivated land resource evaluation research, we usually need to select a large number of indicators for evaluation, but because the nature of these indicators differs, their ranges also differ significantly, so they cannot directly comparable, and in particular they cannot be directly combined in a comprehensive evaluation. Therefore, it is necessary to find a method so that all indicators can be converted into values that can be evaluated uniformly [52]. In the design of this calculation method, the range of each evaluation indicator is set to $[0,100]$, and then the calculated values of all indicators are converted through the system conversion index, where reaching 100 means that the cultivated land resource endowment is high and the condition is excellent, and reaching 0 means that the cultivated land resource endowment is low and the condition is poor. In this way, weighted summation can be conducted to obtain the final comprehensive index value for the overall evaluation. In the process of conversion, the main mathematical methods that can be used are power conversion, satisfaction conversion, grading, a reciprocal method, etc., which can be selected according to need.

1. Evaluation indicators of cultivated land quantity

The cultivated land quantity index is the basic index in the whole cultivated land use system. It can be divided into absolute quantity indicator and relative quantity indicator. The former refers to the total area of cultivated land, which reflects the richness of the overall cultivated land resource in the province. The latter mainly refers to the per capita cultivated land area, which reflects the amount of cultivated land per capita in the province.

(1) Index of total area $\left(I_{T A}\right)$

The total area of cultivated land plays an important role in the total grain output and food security of a country and region. At present, the latest cultivated land data available in China are the survey data pertaining to land use status change at the end of 2017 [53], i.e. $134,881,218.29$ ha. The cultivated land quantity of 31 provinces in China varies greatly, with the largest difference of $1584.57 \times 10^{4}$ ha in Heilongjiang Province and $19.16 \times 10^{4}$ ha in Shanghai at the minimum, with a difference of 82.7 times between them. To reflect the total amount of cultivated land resources in the province and the actual situation in China, the following formula is used to calculate $I_{T A}$ :

$$
I_{T A}=\frac{T A_{i}}{T A_{\max }} \times 100
$$

In Eq. (12), $T A_{i}$ is the total area of cultivated land in province $i$. Here we take the average value from the year of completion of the second national land survey (2009) to that in 2017. $T A_{\max }$ is the maximum value of the total cultivated land area of provinces in China, and the average value from 2009 to 2017 is also taken.
(2) Index of area per capita $\left(I_{A P C}\right)$

Considering the obvious differences in population, total land area, and cultivated land area among the province-level administrative regions in China, it is not enough to consider only the absolute abundance indicator. Therefore, we introduce a relative indicator: cultivated land area per capita:

$$
I_{A P C}=\frac{A P C_{i}}{A P C_{\text {max }}} \times 100
$$

In Eq. (13), $A P C_{i}$ is the per capita cultivated land area of province $i, A P C_{\max }$ is the maximum per capita cultivated land area of provinces in China. These two indicators are taken as the average value from 2009 to 2017.

2. Evaluation indicators of cultivated land quality

The quality of cultivated land has a fundamental impact on the per unit yield of cultivated land. To a large extent, the unit yield level of cultivated land reflects the quality of cultivated land. From the perspective of the availability of basic data for this evaluation, in recent years, the Ministry of Land and Resources and the Ministry of Agriculture and Rural Areas have published the National Cultivated Land Quality Survey and Evaluation results [21-24], but in the Announcement of National Arable Land Quality Grading in 2019 issued by the Ministry of Agriculture and Rural Areas only national data, no provincial data, are used. While the Announcement on the Release of the Main Data Results of the 2016 National Cultivated Land Quality Grades Updating Evaluation released by the Ministry of Land and Resources in December 2017 [22] (the Appendix thereto) the cultivated land quality status of 31 provinces in China (i.e., areas of 15 cultivated land grades in each province) is published, so it can be used for the comprehensive evaluation of cultivated land resources. However, it should be noted that the evaluation of 15 grades of cultivated land quality established by the Ministry of Land and Resources is the evaluation standard for determining the quality of cultivated land by comprehensively considering the annual yield thereof. The $15^{\text {th }}$ grade consists of cultivated land with the lowest yield per unit area of grain, and its annual production capacity is about $1500 \mathrm{~kg} / \mathrm{ha}$, and so on in increments $1500 \mathrm{~kg} / \mathrm{ha}$. The annual production capacity of first-grade land is 22,500 $\mathrm{kg} / \mathrm{ha}$ [21]. According to this standard, the annual production capacity of the province is not consistent with the actual yield: for example, according to the Announcement on the Release of the Main Data Results of the 2016 National Cultivated Land Quality Grades Updating Evaluation by the Ministry of Land and resources, the average cultivated land quality grade of Inner Mongolia is 14.02 when using the area-weighting method, so the annual production capacity is about 3000 $\mathrm{kg} / \mathrm{ha}$, however, the average grain yield in Inner Mongolia from 2009 to 2019 has reached $4697.8 \mathrm{~kg} / \mathrm{ha}$, which is 1.57 times its annual production capacity, which is illogical. Other provinces also have the same problem. To make up for this deficiency, we not only used the cultivated land quality grade survey and evaluation the data released by the Ministry of Land and Natural Resources, but also considered the actual yield of each 
province, and combined both to evaluate the provincial cultivated land quality.

(1) Index of quality grade $\left(I_{Q G}\right)$

Firstly, the average quality grade $\left(V_{A Q G i}\right)$ of each province-level administrative region is calculated by an area-weighting method, and then $I_{Q G}$ is calculated by maximum method. The calculation is determined as follows:

$$
\begin{gathered}
V_{A Q G_{i}}=100 \times \sum_{j=1}^{15}\left(\frac{T A_{i j}}{T A_{i}} \times \frac{16-j}{15}\right) \\
I_{Q G}=\frac{V_{A Q G i}}{V_{A Q G_{\max }}} \times 100
\end{gathered}
$$

In Eqs. (14) and (15), $T A_{i j}$ is the cultivated land area of cultivated land quality grade $j$ in province $i . T A_{i}$ is the total area of cultivated land in province $i . j$ is the quality grade of cultivated land ( 15 grades in total). For the first grade $j$ $=1$, second grade $j=2$, and so on. $V_{A Q G m a x}$ is the maximum value of the average grade of the provincial cultivated land quality in China.

(2) Index of annual grain yield per unit area of cultivated land $\left(I_{A G Y}\right)$

Referring to the above indicators, the maximum method (i.e. the comparison between the maximum value of annual grain yield per unit of cultivated land in a province and the maximum in the whole country) is used to calculate $I_{A G Y}$. The calculation is determined as follows:

$$
I_{A G Y}=\frac{V_{A G Y i}}{V_{A G Y \max }} \times 100
$$

3. Evaluation indicators of cultivated land ecological danger

The evaluation index of cultivated land ecological danger covers a wide range, mainly including soil erosion, natural disasters, soil pollution, etc. From the perspective of the availability of basic data, although the Ministry of Environmental Protection and the Ministry of Land and Natural Resources issued the Bulletin of the National Survey of Soil Pollution in 2014, the first survey obtained the proportion of soil pollution points in different land grades such as cultivated land in China, as well as the proportion of slight, mild, moderate, and severe pollution points [31], but the survey data of each province-level administrative region were not published. In another development, all provinces have completed the detailed survey of soil pollution by the end of 2018, but the specific data have not been published. Therefore, the evaluation does not consider the cultivated land soil pollution indicators.

(1) Index of soil loss $\left(I_{S L}\right)$

Soil loss is the product of many unreasonable development and utilisation activities of land resources, such as destroying forest and grass to open up wasteland, steep slope farming, etc., which is known as the principal ecological environment problem in recent years. The soil loss index is an indicator to reflect the scale and intensity of soil loss in a province. It is characterised by soil loss area and loss intensity indices. It should be noted that, since, at national level, there has not yet been a special soil loss survey on cultivated land, the latest data that can be collected at present are those pertaining to monitoring data in a soil loss survey commissioned by the Ministry of Water Resources in 2018, including the total area of soil loss and the areas of various intensity levels of soil loss in 31 provinces. However, it should be noted that cultivated land is subject to severe human disturbance due to the whole process of crop management and planting (such as soil ploughing, soil preparation, sowing, loosening, weeding, fertilisation, and harvesting) that is readily causes severe soil loss in many places. Taking Yunnan Province as an example, according to Yang Zisheng et al. [34], the total amount of cultivated land soil loss in the whole province accounts for about $70 \%$ to $75 \%$ of the total annual average soil loss from the land. In addition, soil loss from other types of land often become an important ecological and environmental factor, affecting the use of cultivated land. Therefore, in the current situation of a lack of data relating to soil loss from cultivated land in each province-level administrative region, we temporarily used the monitoring data from the soil and water loss survey commissioned by the Ministry of Water Resources in 2018 for analysis and evaluation.

(1) Index of soil loss area $\left(I_{S L A}\right)$

The common index reflecting the scale of regional soil loss is the rate of soil loss area $\left(R_{S L A}\right)$, which refers to the percentage ratio of soil loss area to total land area. According to the Standard for Classification and Gradation of Soil Erosion issued by the Ministry of Water Resources (1997), the area of soil erosion here refers to the area subject to a minimum of mild erosion. The calculation is determined as follows:

$$
R_{L S A}=\frac{A_{S L}}{A_{T L}} \times 100 \%
$$

In Eq. (17), $A_{S L}$ indicates the area of soil loss; $A_{T L}$ indicates the total land area.

The higher the value of $R_{S L A}$, the more scale (range) of soil erosion suffered and the ecological environment degrades. According to the above method, the calculated values of $R_{S L A}$ need to be converted to ensure that the result is within $[0,100]$. The converted index value is called the index of soil loss area $\left(I_{S L A}\right)$ :

$$
I_{S L A}=100-\left(R_{S L A} \times 100\right)
$$

The greater the value of the $I_{S L A}$, the lower the proportion of soil loss in a certain area, and the better the ecological environment.

(2) Index of soil loss intensity $\left(I_{S L I}\right)$

In the current investigation and study of soil loss in China, the intensity grade of soil erosion is generally classified by soil erosion modulus. Soil erosion modulus $(S E M)$ refers to the average annual soil erosion amount per unit land area in a certain region (or watershed), and its unit is $\mathrm{t} / \mathrm{km}^{2} \cdot \mathrm{y}$. It is the main index used to characterise the intensity of soil loss. According to the Standard for Classification and Gradation of Soil Erosion [54] issued by the Ministry of Water Resources in January 2008, soil erosion grades are divided into slight erosion, mild erosion, moderate erosion, intensity erosion, extreme intensity erosion, and severe erosion. The SEM values are $<500 \mathrm{t} / \mathrm{km}^{2} \cdot \mathrm{y}$ (north-east black soil area, northern rock mountain area and wind erosion area are $<200 \mathrm{t} / \mathrm{km}^{2} \cdot \mathrm{y}$; north-west loess plateau area is $<1000 \mathrm{t} / \mathrm{km}^{2} \cdot \mathrm{y}$ ), $\geq 500$ 
(200, 1000) but $<2500 \mathrm{t} / \mathrm{km}^{2} \cdot \mathrm{y}, \geq 2500$ but $<5000$ $\mathrm{t} / \mathrm{km}^{2} \cdot \mathrm{y}, \geq 5000$ but $<8000 \mathrm{t} / \mathrm{km}^{2} \cdot \mathrm{y}, \geq 8000$ but $<$ $15000 \mathrm{t} / \mathrm{km}^{2} \cdot \mathrm{y}, \geq 15000 \mathrm{t} / \mathrm{km}^{2} \cdot \mathrm{y}$. The soil loss grades in the soil loss survey and monitoring the data published by the Ministry of Water Resources in 2018 include mild erosion, moderate erosion, intense erosion, and worse. According to this, when calculating the average soil erosion modulus of each province, the SEM of each erosion grade is as follows: $200 \mathrm{t} / \mathrm{km}^{2} \cdot \mathrm{y}$ for slight erosion, $1500 \mathrm{t} / \mathrm{km}^{2} \cdot \mathrm{y}$ for mild erosion, $3750 \mathrm{t} / \mathrm{km}^{2} \cdot \mathrm{y}$ for moderate erosion, and $12,000 \mathrm{t} / \mathrm{km}^{2} \cdot \mathrm{y}$ for intense erosion and worse. On this basis, the total annual soil loss and average soil erosion modulus of each province can be calculated, and then $I_{S L I}$ can be calculated according to the following formula:

$$
I_{S L A}=100-\left(\frac{S E M_{i}}{S E M_{N A}} \times 100\right)
$$

In Eq. (19), $S E M_{i}$ indicates the soil erosion modulus for province $i ; S E M_{N A}$ indicates the national average soil erosion modulus of soil-eroded land in China. It also is the average amount of soil erosion per unit soil loss area (the sum of the areas of mild erosion, moderate erosion, intense erosion, and worse). According to the survey and monitoring results published by the Ministry of Water Resources in 2018, the $S E M_{N A}$ value is $4128.64 \mathrm{t} / \mathrm{km}^{2} \cdot \mathrm{y}$. The higher the value of $I_{S L I}$, the lower the intensity of soil loss, and the better the ecological environment.

(2) Index of natural disaster $\left(I_{N D}\right)$

Natural disasters are an important factor affecting the output and efficiency of cultivated land use. At present, the annual China Statistical Yearbook has included a comprehensive range of area of disaster-affected crops and area of disaster-destroyed crops caused by drought, floods, landslides, debris flows, typhoons, hailstorms, and ice and snow disasters, which provides a basis for this evaluation. Here, the disaster area and disaster intensity are also used to characterise $I_{N D}$.

(1) Index of disaster-affected crops area $\left(I_{D C A}\right)$

Referring to the calculation method of $I_{S L A}$, the following formula is adopted for calculation:

$$
I_{D C A}=100-\left(\frac{A_{D C}}{A_{T S}} \times 100\right)
$$

In Eq. (20), $A_{D C}$ indicates area of disaster-affected crops; $A_{T S}$ indicates the total sown area of crops.

The higher value of $I_{S L A}$, the lower the areal proportion of disaster-affected crop, and the better the ecological environment.

(2) Index of grain production reduced by disaster $\left(I_{G P D}\right)$

According to the Natural Disaster Information Statistics [55], in the agricultural disaster statistics, it is necessary to count areas of disaster-affected crops, area of disaster-damaged crops, and area of disaster-destroyed crops. These three indicators can reflect the difference in severity of a disaster. They respectively refer to the planting area of crops whose crop yield is reduced by $10 \%$ or more, $30 \%$ or more, and $80 \%$ or more than in a normal year due to natural disasters. According to this, we can calculate the amount of grain reduced due to each disaster and reflect the intensity of the disaster therein. In recent years, the China Statistical Yearbook has included areas of disaster-affected crops and area of disaster-destroyed crops in each province-level administrative region, but omitted the intermediate-level area. Therefore, the following method is used to calculate the grain production as reduced by disaster $\left(G P_{D}\right)$ :

$$
G P_{D}=\left[C_{1} \times\left(A_{A C}-A_{D C}\right)+C_{2} \times A_{D C}\right] \times A Y_{U A}
$$

In Eq. (21), $A_{A C}$ indicates area of disaster-affected crops, taking the average value from 2009 to 2019. $A_{D C}$ indicates area of disaster-destroyed crops, taking the average value from 2009 to 2019 . $A Y_{U A}$ indicates average yield per unit area of grain crops, also taking the average value from 2009 to 2019; $C_{1}$ and $C_{2}$ respectively indicate production reduction coefficients of disaster-affected areas and disaster-destroyed areas, with average values of 0.375 and 0.900 .

The index of grain production reduced by disaster $\left(I_{G P D}\right)$ indicates the comparative relationship between the amount of grain reduced due to disasters and the total grain output as calculated by:

$$
I_{G P D}=100-\left(\frac{G P_{D}}{A O_{G}} \times 100\right)
$$

In Eq. (22), $G P_{D}$ indicates the grain production as reduced by disaster; $T O_{G}$ indicates the total output of grain. The higher the value of $I_{G P D}$, the lower the degree of grain production reduced by disaster, and the better the ecological environment.

\section{Results and Analysis}

\subsection{Quantitative Comprehensive Evaluation Results of Cultivated Land Resources}

According to the above comprehensive evaluation method of cultivated land resources based on the TOPSIS-Grey Relational Analysis Method, the index of farmland quantity $\left(I_{F Q I}\right)$, index of farmland quality $\left(I_{F Q 2}\right)$, index of ecological danger $\left(I_{E D}\right)$, and comprehensive index of farmland resource $\left(C I_{F R}\right)$ of 31 provinces are calculated (Table 2). According to the calculated results, the classification and spatial distribution of each index can be analysed, and the comprehensive endowment and superiority of cultivated land resources in each province can be analysed and ranked, respectively.

Table2. Cultivated land quantity index, quality index, ecological danger index, and comprehensive index of each province in China.

\begin{tabular}{|c|c|c|c|c|c|}
\hline Region & $\boldsymbol{I}_{\boldsymbol{F Q} \boldsymbol{I}}$ & $\boldsymbol{I}_{\boldsymbol{F Q} \boldsymbol{2}}$ & $\boldsymbol{I}_{\boldsymbol{E D} \boldsymbol{D}}$ & $\boldsymbol{C I}_{\boldsymbol{F R}}$ & $\begin{array}{c}\text { Compre- } \\
\text { hensive } \\
\text { ranking } \\
\text { of } \boldsymbol{C I}_{\boldsymbol{F R}}\end{array}$ \\
\hline Beijing & 14.78 & 45.46 & 69.30 & 25.57 & 30 \\
\hline Tianjin & 16.92 & 37.95 & 81.20 & 27.24 & 29 \\
\hline Hebei & 35.98 & 40.97 & 61.98 & 40.94 & 9 \\
\hline Shanxi & 31.70 & 24.19 & 31.98 & 29.75 & 28 \\
\hline Inner Mongolia & 65.93 & 18.22 & 15.72 & 37.41 & 15 \\
\hline Liaoning & 34.11 & 32.89 & 48.45 & 36.02 & 16 \\
\hline Jilin & 51.37 & 36.14 & 57.09 & 48.12 & 3 \\
\hline
\end{tabular}




\begin{tabular}{|c|c|c|c|c|c|}
\hline Region & $\boldsymbol{I}_{\boldsymbol{F Q I} \boldsymbol{I}}$ & $\boldsymbol{I}_{\boldsymbol{F Q} \boldsymbol{Z} \boldsymbol{2}}$ & $\boldsymbol{I}_{\boldsymbol{E} \boldsymbol{D}}$ & $\boldsymbol{C}_{\boldsymbol{F} \boldsymbol{R} \boldsymbol{R}}$ & $\begin{array}{c}\text { Compre- } \\
\text { hensive } \\
\text { ranking } \\
\text { of } \boldsymbol{C I}_{\boldsymbol{F R}}\end{array}$ \\
\hline Heilongiang & 85.50 & 27.45 & 58.14 & 60.73 & 1 \\
\hline Shanghai & 14.50 & 82.73 & 84.28 & 30.23 & 27 \\
\hline Jiangsu & 28.68 & 72.97 & 79.29 & 43.09 & 6 \\
\hline Zhejiang & 20.63 & 50.65 & 63.19 & 31.31 & 25 \\
\hline Anhui & 34.88 & 52.85 & 70.19 & 43.71 & 5 \\
\hline Fujian & 19.07 & 58.42 & 72.11 & 31.70 & 22 \\
\hline Jiangxi & 25.71 & 67.30 & 63.78 & 38.14 & 14 \\
\hline Shandong & 37.86 & 58.66 & 67.00 & 46.61 & 4 \\
\hline Henan & 39.72 & 66.66 & 72.16 & 50.08 & 2 \\
\hline Hubei & 32.92 & 67.35 & 53.62 & 42.68 & 8 \\
\hline Hunan & 27.87 & 71.43 & 60.62 & 40.18 & 10 \\
\hline Guangdong & 21.46 & 69.45 & 68.44 & 35.05 & 19 \\
\hline Guangxi Zhuang & 30.91 & 48.40 & 62.78 & 39.10 & 12 \\
\hline Hainan & 22.06 & 43.48 & 58.59 & 30.95 & 26 \\
\hline Chongqing & 25.33 & 46.31 & 56.52 & 33.83 & 20 \\
\hline Sichuan & 35.93 & 49.07 & 61.75 & 42.68 & 7 \\
\hline Guizhou & 34.31 & 29.22 & 50.17 & 35.35 & 17 \\
\hline Yunnan & 38.70 & 32.91 & 47.29 & 38.59 & 13 \\
\hline Tibet & 27.17 & 23.56 & 74.65 & 31.49 & 23 \\
\hline Shaanxi & 30.97 & 28.50 & 46.12 & 32.62 & 21 \\
\hline Gansu & 43.32 & 18.62 & 22.58 & 31.46 & 24 \\
\hline Qinghai & 23.78 & 20.61 & 40.29 & 25.27 & 31 \\
\hline Ningxia Hui & 33.61 & 30.52 & 48.64 & 35.10 & 18 \\
\hline Xinjiang Uygur & 44.42 & 36.07 & 31.96 & 39.82 & 11 \\
\hline & & & & & \\
\hline
\end{tabular}

\subsection{Quantity, Quality, and Ecological Danger of Cultivated Land}

\section{Quantity of cultivated land}

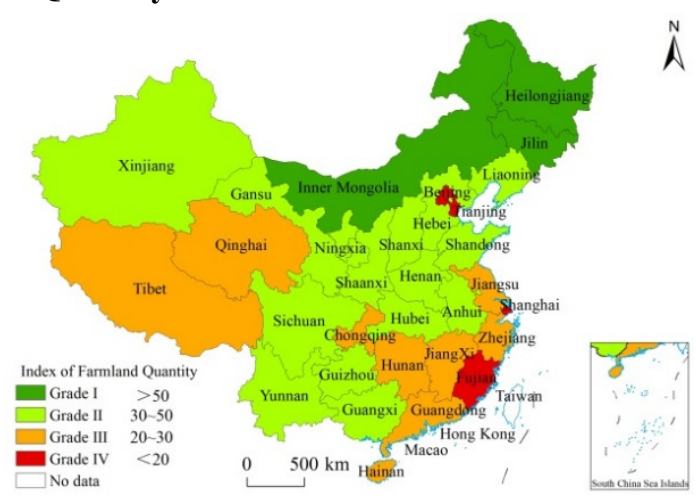

(a)

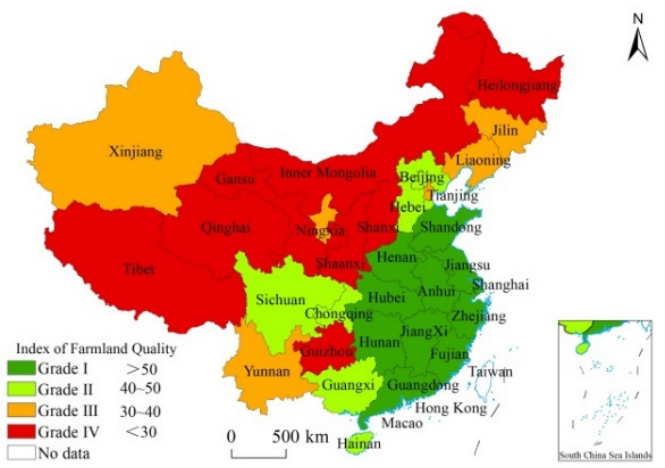

(b)

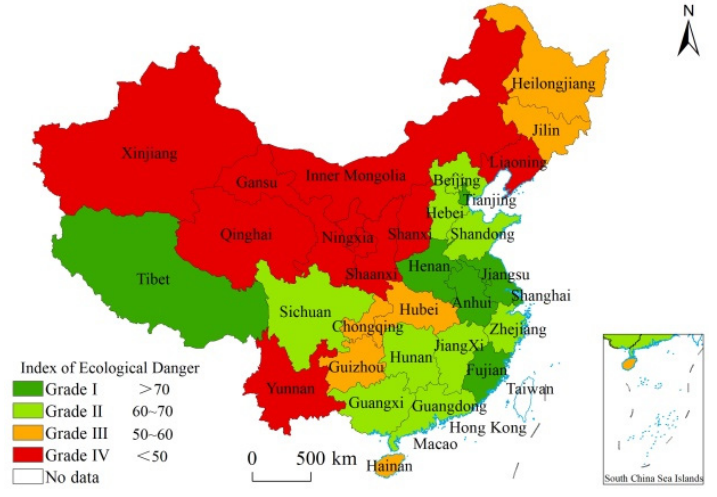

(c)

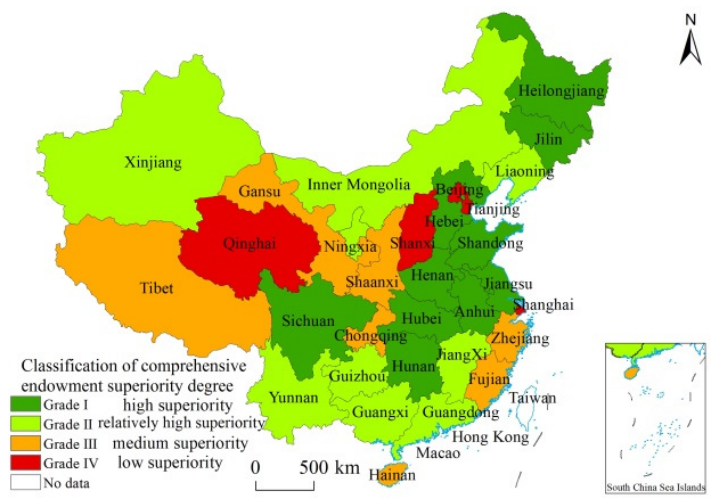

(d)

Figure 1. Classification map of cultivated land quantity, quality, ecological danger, and comprehensive endowment dominance in China. (a) Classification of index of farmland quantity; (b) Classification of index of farmland quality. (c)

Classification of index of farmland ecological danger; (d)

Classification of comprehensive endowment superiority degree of farmland resources.

In terms of the quantity of cultivated land, $I_{F Q l}$, which is determined by the total area of cultivated land and the per capita cultivated land area, have obvious differences among provinces. The $I_{F Q 1}$ values of Heilongiiang Province, Inner Mongolia Autonomous Region, and Jilin Province are 85.50, 65.93, and 51.37 respectively. Among them, the $I_{F Q I}$ value of Heilongjiang Province is 5.9 times higher than that of Shanghai $\left(I_{F Q I}\right.$ value $\left.=14.50\right)$ which is the lowest in China. These are followed by Xinjiang Uygur Autonomous Region, Gansu Province, Henan Province, Yunnan Province, Shandong, Hebei Province, and Sichuan Province. The $I_{F Q 1}$ values of these seven provinces are about 35 to 45 . The $I_{F Q I}$ values of Anhui Province, Guizhou Province, Liaoning Province, Ningxia Hui Autonomous Region, Hubei Province, Shanxi Province, Shaanxi Province, and Guangxi Zhuang Autonomous Region are about 30 to 35 . The $I_{F Q I}$ values of Jiangsu Province, Hunan Province, Tibet Autonomous Region, Jiangxi Province, Chongqing, Qinghai Province, Hainan Province, Guangdong Province, and Zhejiang Province are relatively low, at about 20 to 30 . Fujian Province, Tianjin, Beijing, and Shanghai have the lowest endowment of cultivated land, the $I_{F Q I}$ values of the four provinces are all below 20. According to this, the $I_{F Q I}$ of each province can be divided into four levels (Fig. 1a). Among them, provinces with an $I_{F Q I}$ value above 30 (i.e. 
belonging to Grade I or II) mean that their cultivated land quantity has obvious superiority.

\section{Quality of cultivated land}

In terms of the quality of cultivated land, the $I_{F Q 2}$ determined by the quality grade of cultivated land and the annual grain yield per unit area of cultivated land in each province differ significantly. The $I_{F Q 2}$ values of Shanghai, Jiangsu Province, and Hunan Province are 82.73, 72.97, and 71.43 respectively. Among them, the $I_{F Q 2}$ value of Shanghai is 4.5 times higher than that of Inner Mongolia Autonomous Region $\left(I_{F Q 2}\right.$ value $\left.=18.22\right)$ which is the lowest in China. In Guangdong Province, Hubei Province, Jiangxi Province, Henan Province, Shandong Province, Fujian Province, Anhui Province, and Zhejiang Province, the $I_{F Q 2}$ values of these eight provinces are about 50 to 70 followed by Sichuan Province, Guangxi Zhuang Autonomous Region, Chongqing, Beijing, Hainan Province, and Hebei Province. The $I_{F Q 2}$ values of the six provinces are about 40 to 50 . The $I_{F Q 2}$ values of Tianjin, Jilin Province, Xinjiang Uygur Autonomous Region, Yunnan Province, Liaoning Province, and Ningxia Hui Autonomous Region are relatively low, at about 30 to 40 . The lowest $I_{F Q 2}$ values are in Guizhou Province, Shaanxi Province, Heilongjiang Province, Shanxi Province, Tibet Autonomous Region, Qinghai Province, Gansu Province, and Inner Mongolia Autonomous Region. The $I_{\mathrm{FQ} 2}$ values of the eight provinces are all below 30, and the $I_{F Q 2}$ values of Gansu Province and Inner Mongolia Autonomous Region are both below 20. According to this, the $I_{F Q 2}$ of each province is divided into four levels (Fig. 1b). Provinces with $I_{F Q 2}$ values of above 40 (i.e. belonging to Grades I or II) mean that their cultivated land quality conditions have obvious superiority.

\section{Ecological danger of cultivated land}

In terms of cultivated land ecological danger situation, the differences of index of farmland ecological danger $\left(I_{E D}\right)$ in different provinces determined by soil loss status (soil loss area ratio and soil loss intensity) and cultivated land natural disaster status (area proportion of disasteraffected crops and grain production reduced by disaster) exhibit relatively significant differences. The lowest ecological danger to cultivated land (meaning the highest value of $I_{E D}$ ) is in Shanghai and Tianjin, where the $I_{E D}$ values are 84.28 and 81.20 respectively. Among them, $I_{E D}$ value of Shanghai is 5.4 times higher than that of Inner Mongolia Autonomous Region $\left(I_{E D}\right.$ value $\left.=15.72\right)$ which is the lowest in China followed by Jiangsu Province, Tibet Autonomous Region, Henan Province, Fujian Province, and Anhui Province, the $I_{E D}$ value of these five provinces is about 70 to 80 . The third tier of $I_{E D}$ values occur in Beijing, Guangdong Province, Shandong, Jiangxi Province, Zhejiang Province, Guangxi Zhuang Autonomous Region, Hebei Province, Sichuan Province, and Hunan Province. The $I_{E D}$ values of these nine provinces are about 60 to 70 . The $I_{E D}$ values of Hainan Province, Heilongjiang Province, Jilin Province, Chongqing, Hubei Province, and Guizhou Province are about 50 to 60 . The relatively low values of $I_{E D}$ occur in Ningxia Hui Autonomous Region, Liaoning Province, Yunnan Province, Shaanxi Province, Qinghai Province, Shanxi Province, Xinjiang Uygur Autonomous Region,
Gansu Province, and Inner Mongolia. The $I_{E D}$ values of the nine provinces are all below 50. Among them, the $I_{E D}$ values of Gansu Province and Inner Mongolia Autonomous Region are all below 23. It can be seen that indices of ecological danger in most provinces are relatively high. Here, the index of ecological danger in each province is divided into four levels (Figure 1c). Among them, provinces with an $I_{F Q 1}$ value of above 50 (i.e., belonging to Grades I, II, or III) mean that the ecological danger of cultivated land is relatively slight and the ecological environments remain in good condition.

\subsection{Classification of Comprehensive Endowment Superiority of Cultivated land Resources}

Table 2 shows that the comprehensive index of farmland resources $\left(C I_{F R}\right)$ determined by $I_{F Q 1}, I_{F Q 2}$ and $I_{E D}$ differs significantly. Heilongjiang Province has the best comprehensive endowment condition of cultivated land resources, and its $C I_{F R}$ value is 60.73 , which is 2.4 times that of Qinghai Province $\left(C I_{F R}\right.$ value is 25.27$)$ which is the smallest in China.

The further to analyse the difference of comprehensive degree of endowment of farmland resources in 31 provinces in China, the natural breakpoint method provided by ArcGIS software is used here based on the natural classification of $C I_{F R}$ with appropriate adjustments. Finally, the comprehensive endowment superiority of cultivated land resources of 31 province-level administrative regions in China is divided into four grades: high superiority, relatively high superiority, intermediate superiority, and low superiority.

The results (Fig. 1d) show that the $C I_{F R}$ values of Heilongjiang Province, Henan Province, Jilin Province, Shandong Province, Anhui Province, Jiangsu Province, Sichuan Province, Hubei Province, Hebei Province, and Hunan Province are all above 40: these are the 10 provinces with the highest comprehensive degree of endowment superiority of cultivated land resources in China, belonging to the first level — "high superiority". The $C I_{F R}$ values of Xinjiang Uygur Autonomous Region, Guangxi Zhuang Autonomous Region, Yunnan Province, Jiangxi Province, Inner Mongolia Autonomous Region, Liaoning Province, Guizhou Province, Ningxia Hui Autonomous Region, and Guangdong Province are about 35 to 40 . These are the nine provinces with relatively high comprehensive endowment superiority of cultivated land resources in China, belonging to the second level "relatively high superiority". The $C I_{F R}$ values of Chongqing, Shaanxi Province, Fujian Province, Tibet Autonomous Region, Gansu Province, Zhejiang Province, and Hainan Province are between 31 and 34. From the national level, the comprehensive endowment statuses of cultivated land resources in these seven provinces are at an intermediate level, belonging to the third level "intermediate superiority". The $C I_{F R}$ values of Shanghai, Shanxi Province, Tianjin, Beijing, and Qinghai Province are relatively low, ranging from 25 to 30 . From the national level, the comprehensive endowment of cultivated land resources in these five provinces is at a low level, belonging to the fourth level - "low superiority". 
It is worth noting that the 10 provinces with relatively high comprehensive endowment superiority and nine provinces with relatively high dominance degree of cultivated land resources are usually those provinces with relatively large total grain output. According to China Statistical Yearbook, among the 13 provinces with an average annual grain output of more than 20 million tons from 2009 to 2019, there are 10 provinces (i.e., Heilongjiang Province, Henan Province, Shandong Province, Anhui Province, Jilin Province, Jiangsu Province, Hebei Province, Sichuan Province, Hunan Province, and Hubei Province) classified as "high superiority" provinces with a high comprehensive endowment superiority of cultivated land resources in China and there are three provinces (i.e., Inner Mongolia Autonomous Region, Jiangxi Province, and Liaoning Province) classified as "relatively high superiority" provinces with relatively high comprehensive endowment of cultivated land resources.

\subsection{Classification of the Types of Superiority of Cultivated Land Resources in Different Provinces}

According to the classification of $I_{F Q 1}, I_{F Q 2}$, and $I_{E D}, 31$ provinces in China can be classified into six categories (Fig. 2): (1) superiority in quantitative terms; (2) superiority in quantity and ecology terms; (3)superiority in quality and ecology terms; (4) superiority in ecology terms; (5)comprehensive superiority; (6) unclear.

Among the 19 "high superiority" and "relatively high superiority" provinces, the superiority categories of each province differ and can be roughly divided into four categories. The first is superiority in quantitative terms, including Xinjiang Uygur Autonomous Region, Inner Mongolia Autonomous Region, Yunnan Province, Liaoning Province, and Ningxia Hui Autonomous Region. The second is superiority in terms of quantity and ecology, including Heilongjiang Province, Jilin Province, and Guizhou Province. The third is superiority in terms of quality and ecology, including Jiangsu Province, Hunan Province, Jiangxi Province, and Guangdong Province. The fourth is comprehensive superiority, including Henan Province, Shandong Province, Anhui Province, Hebei Province, Sichuan Province, Hubei Province, and Guangxi Zhuang Autonomous Region.

Even among the 14 provinces with "medium superiority" and "low superiority" whose comprehensive endowment superiority of cultivated land resources is not prominent, they will have obvious superiority in terms of quantity, quality, or ecology (although their classification is below that of "high superiority" and "relatively high superiority" provinces), which can be divided into four categories. The first is superiority in quantitative terms, including Shaanxi Province, Gansu Province, and Shanxi Province. The second is superiority in terms of quality and ecology, including Chongqing, Fujian Province, Zhejiang Province, Shanghai, Beijing, and Hainan Province. The third is superiority in terms of ecology, including Tianjin and Tibet Autonomous Region. The fourth is unclear, such as Qinghai Province.
The majority of provinces have a "single" superiority, a "double" superiority, or comprehensive superiority, which provides a direction and path for the provinces to develop, utilise, and protect their limited cultivated land resources in a rational manner.

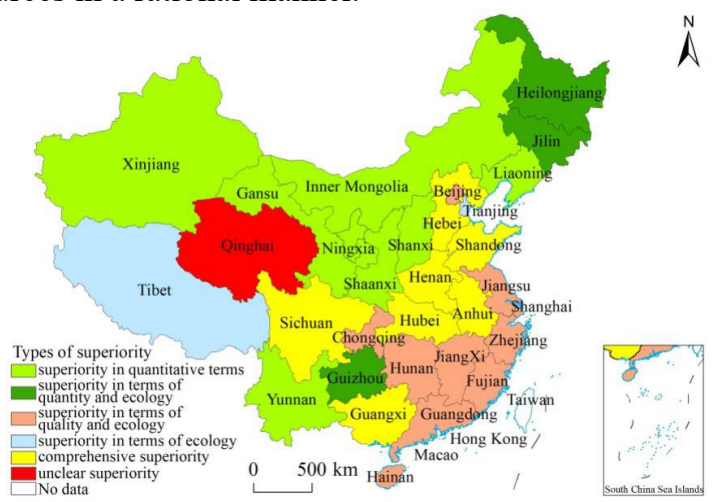

Figure 2. Types of superiority in terms of cultivated land resources in each province of China.

\section{Conclusions and Discussions}

\subsection{Main Conclusions}

The evaluation of cultivated land resources at the national level is an important basis for the country to formulate the plan of cultivated land utilisation and renovation, the policy of cultivated land protection and decision-making around land space management. It is necessary to establish a comprehensive evaluation indicator system and quantitative calculation method of cultivated land resources, which integrates quantitative evaluation, quality evaluation, and ecological danger assessment. In this paper, based on TOPSIS-Grey Relational Analysis Method, the province-level administrative region is taken as the analysis and evaluation unit, and the three dimensions of cultivated land: quantity, quality, and ecological danger are combined to construct a practical and feasible comprehensive evaluation indicator system and quantitative calculation method of cultivated land resources in China, to measure and compare the superiority, inferiority, and comprehensive endowment of cultivated land resources in various provinces.

The results show that Heilongjiang Province, Henan Province, Jilin Province, Shandong Province, Anhui Province, Jiangsu Province, Sichuan Province, Hubei Province, Hebei Province, and Hunan Province are ten "high superiority" provinces with the high comprehensive endowment of cultivated land resources in China. Xinjiang Uygur Autonomous Region, Guangxi Zhuang Autonomous Region, Yunnan Province, Jiangxi Province, Inner Mongolia Autonomous Region, Liaoning Province, Guizhou Province, Ningxia Hui Autonomous Region, and Guangdong Province are nine "relatively high superiority" provinces with relatively high comprehensive endowment of cultivated land resources in China. These provinces are also those with more total grain output in China. There are 13 provinces with an average total grain output of more than 20 million tons from 2009 to 2019 belonging to the scope of the above-mentioned "high superiority" provinces or "relatively high superiority" provinces. 
From the "single" superiority degree of cultivated land quantity, quality, and ecological danger, Heilongjiang Province, Inner Mongolia Autonomous Region, and Jilin Province are the more prominent in the field of quality, whose $I_{F Q 1}$ values exceed 50 . Next are 15 provinces: Xinjiang Uygur Autonomous Region, Gansu Province, Henan Province, Yunnan Province, Shandong Province, Hebei Province, Sichuan Province, Anhui Province, Guizhou Province, Liaoning Province, Ningxia Hui Autonomous Region, Hubei Province, Shanxi Province, Shaanxi Province, and Guangxi Zhuang Autonomous Region with relatively high $I_{F Q I}$ values of between 30 and 50. The cultivated land qualities of Shanghai, Jiangsu Province, Hunan Province, Guangdong Province, Hubei Province, Jiangxi Province, Henan Province, Shandong Province, Fujian Province, Anhui Province, and Zhejiang Province in central and eastern regions are better. The $I_{F Q 2}$ values of these 11 provinces exceed 50. These are followed by Sichuan Province, Guangxi Zhuang Autonomous Region, Chongqing, Beijing, Hainan Province, and Hebei Province, and the $I_{F Q 2}$ values of these six provinces are between 40 and 50. In terms of cultivated land ecological danger, Shanghai, Tianjin, Jiangsu Province, Tibet Autonomous Region, Henan Province, Fujian Province, and Anhui Province have greater superiority, and the $I_{E D}$ values of these seven provinces exceed 70 . These are followed by Beijing, Guangdong Province, Shandong Province, Jiangxi Province, Zhejiang Province, Guangxi Province, Hebei Province, Sichuan Province, Hunan Province, Hainan Province, Heilongjiang Province, Jilin Province, Chongqing, Hubei Province, and Guizhou Province. The $I_{E D}$ values of these provinces are between 50 and 60 .

The 31 provinces are classified into six categories: (1) superiority in quantitative terms; (2) superiority in terms of quantity and ecology; (3)superiority in terms of quality and ecology; (4) superiority in terms of ecology; (5)comprehensive superiority; 6) unclear superiority. The cultivated land resources in most provinces have a "single" superiority, "double" superiority, or comprehensive superiority.

\subsection{Discussions}

In the evaluation of cultivated land resources at the national level, it is not enough to evaluate the single index of quantity, quality, or ecology of cultivated land, which is not conducive to objectively and scientifically measuring and comparing the differences in superiority, inferiority, and comprehensive endowment of cultivated land resources in different provinces. In this paper, a quantitative index system and its calculation method for the comprehensive evaluation of cultivated land resources are established to measure systematically the comprehensive condition of cultivated land quantity, quality, and ecological danger in each province, which promotes the development of the traditional land resources evaluation system, and helps to objectively reveal the endowment status and limiting factors of cultivated land resources in each province, and provides the basis for the development, utilisation, and protection strategy decision, comprehensive renovation planning, and management of cultivated land resources according to local conditions. However, this does not mean that the quantitative index system and its calculation method of comprehensive evaluation of cultivated land resources constructed in this paper are only applicable to the evaluation of province-level administrative regions at the national level. This index system and its calculation method are also applicable to the analysis and research across different regional scales, such as city level, county level, and township level, and can even be used as a reference in the analysis and evaluation of the comprehensive status of cultivated land resources between countries.

In view of the complexity of this comprehensive evaluation work and the difficulty of obtaining some indicator data, the evaluation needs to be further improved and perfected. For example, cultivated land soil pollution is an important indicator of ecological danger, however, due to the lack of provincial survey data at the national level, only a few provinces such as Sichuan Province have published provincial survey data at the provincial level, so we could not measure the index. Although the author has attempted to refer to the map of the distribution of heavymetal pollution in surface soil samples in China drawn by Duan Qiannan et al. [33] and relevant reports pertaining to various provinces, and referring to the statistical data of major pollutant emissions, fertiliser application, population density, and other statistical data in the China Statistical Yearbook, and comprehensively judged and roughly calculated the cultivated land soil pollution status index of each province, the results are not perfect. We supplemented this research after the national-level issue of survey data relating to cultivated land soil pollution in each province.

Due to the significant differences in natural and social economic conditions such as landscape, topography, climate, soil, hydrology, population, economy, and other natural and socio-economic conditions of 31 provinces, the quantity, quality, and ecological environment of cultivated land resources in each province also differ to a significant extent, therefore, the spatial distributions of provinces with quantity superiority, quality superiority, and ecological environment superiority are not identical. For example, Heilongjiang is the province with the most prominent quantitative superiority of cultivated land resources in China. Its index of farmland quantity reaches 85.50, ranking first among first level (high superiority) provinces, but its index of farmland quality is only 27.45 , classifying it as a fourth level province. Another example is that the index of farmland quantity of Jiangxi Province is only 25.71 , which belongs to the third level, but its index of farmland quality and ecological danger reach 67.30 and 63.78 respectively, which belong to the first and second levels, respectively. In other words, it has superiority in cultivated land quality and ecological environment, therefore, the comprehensive index of farmland resources in Jiangxi Province reaches 38.14, and the comprehensive endowment superiority is classified at the second level, as it has become one of the major grainproducing provinces in China. 
Based on this, when evaluating the comprehensive endowment of cultivated land resources in each province, we should have such a basic understanding such that: a province has abundant quantity, high quality, and light (or unapparent) ecological danger, which indicates comprehensive superiority of cultivated land resources. However, it cannot be denied that even if the quality of cultivated land is low, even there is a certain ecological crisis, if there is a relatively rich amount of cultivated land, it will also exhibit superiority of cultivated land resources, and remains an important pillar of national food security. Therefore, those provinces with the worst comprehensive endowment and inferiority of cultivated land resources mainly refer to the provinces whose cultivated land quantity is inferior, and the cultivated land quality and ecological conditions are not dominant. According to this understanding, most provinces in China have a certain "single" superiority, a "double" superiority, or comprehensive superiority, which provides an important direction and path for those provinces to develop, utilise, and protect their limited cultivated land resources in a rational manner.

\section{References}

1 Yang Zisheng, Liu Yansui, Zhao Qiaogui, et al. Principles and Methods Regional Food Security Assessment Based on cultivated land Utilization and Its Practice in Yunnan Province [M] . Beijing: China Science and Technology Press, 2017: 1-180.

2 Klingebiel A. A., Montgomery P. H. Land Capability Classification [N]. Washington D.C.: US Department of Agriculture Handbook, 1961, (210): 124.

3 FAO. A framework for land evaluation [N]. Rome: FAO soil bulletin, 1976, (32): 1-25.

4 FAO. Report on the Agr o -ecological Zones Project [N]. Rome: World Soil Resources Reports, 1982, (48):1-4.

5 Dumanski J, Onofrei C. Techniques of crop yield assessment for agricultural land evaluation [J]. Soil Use and Management, 1989, 5(1): 9-15.

6 Bi Yuyun, Zheng Zhenyuan. The actual changes of cultivated area since the founding of new China $[\mathrm{J}]$. Resource Science, 2000

7 FENG Zhiming, LIU Baoqin, YANG Yanzhao. A study of the changing trend of Chinese cultivated land amount and data reconstructing: 1949-2003. Journal of Natural Resources, 2005, 20(1): 35-43.

8 YANG Zisheng. On the necessity of keeping the red line of cultivated land area about 120 million hectares in china and its countermeasures system [C]//LIU Yansui. Research on Sustainable Use of Land Resources and New Countryside Construction in China. Chongqing: Southwest China Normal University press, 2008: 20-26.

9 Xue CAO, Xiaobin JIN, Jinshuo WANG, Lijuan MIAO, Yinkang ZHOU. Reconstruction and change analysis of cropland data of China in recent 300
years[J]. Acta Geographica Sinica, 2014, 69(7): 896906.

10 TAN Yongzhong, HE Ju, YUE Wenze, et al. Spatial pattern change of the cultivated land before and after the Second National Land Survey in China. Journal of Natural Resources, 2017, 32(2): 186-197.

11 GAO Xiaoyu, CHENG Weiming, WANG Nan,et al. Spatio-temporal distribution and transformation of cropland in geomorphologic regions of China during 1990-2015 [J]. Journal of Geographical Sciences, 2019, 29(2): 180-196

12 Zhaohao Lai, Meiqiu Chen, Taoju Liu. Changes in and prospects for cultivated land use since the reform and opening up in China [J]. Land Use Policy, 2020, 97: 104781

13 Yuzhe $\mathrm{Wu}$, Liping Shan, Zhen Guo,Yi Peng. cultivated land protection policies in China facing 2030: Dynamic balance system versus basic cultivated land zoning [J]. Habitat International, 2017, 69: 126-138

14 Xiangzheng Deng, Jikun Huang, Scott Rozelle, Jipeng Zhang, Zhihui Li. Impact of urbanization on cultivated land changes in China [J]. Land Use Policy, 2015, 45: 1-7

15 Yuheng Li,Yurui Li,Hans Westlund,Yansui Liu. Urban-rural transformation in relation to cultivated land conversion in China: Implications for optimizing land use and balanced regional development [J]. Land Use Policy, 2015, 47: 218-224

16 CUI XuFeng, MA YunMeng, ZHANG GuangHong. The factors of cultivated land conversion and its temporal and spatial characteristics: an integrated model [J]. Scientia Agricultura Sinica, 2018, 51(22): 4316-4327.

17 LI Yuan. Land Resources of China [M] . Beijing: China Land Press, 2000. 1-235.

18 Ministry of Land and Resources of the People's Republic of China, National Bureau of Statistics of the People's Republic of China, Office of the Second National Land Survey Leading Group of the State Council. Communique on the key data results of the Second National Land Survey [EB/OL]. (2013-12-30) http://www.china.com.cn/zhibo/zhuanti/chxinwen/2013-12/30/content_31040885.htm.

19 WANG Hao. The Third Land Survey to be completed by 2020[N]. People's Daily, 2019-08$17(2)$.

20 SHI Yulin. Land Resources Data Set of China's 1:1 Million Land Resources Map. Beijing: China Renmin University Press, 1991: 1-45.

21 Ministry of Land and Resources of the People's Republic of China. Press conference on the results of the 2016 national cultivated land quality grades updating evaluation [EB/OL]. (2017-12-26) http://www.scio.gov.cn/xwfbh/gbwxwfbh/ xwfbh/gtzyb/Document/1614366/1614366.htm.

22 The Ministry of Land and Resources of the People's Republic of China. Announcement on the release of 
the main data results of the 2016 national cultivated land quality grades updating evaluation [EB/OL]. (2017-12-21)

http://g.mnr.gov.cn/201712/t20171226_

1711147.html.

23 Department of Agriculture of the People's Republic of China. Bulletin on the quality grades of cultivated land throughout the country [R] . Farmers Daily, 2014-12-18 (7).

24 The Ministry of Agriculture and Rural Affairs of the People' s Republic of China. Announcement of national arable land quality grading in 2019[R]. Gazette of the Ministry of Agriculture and Rural Affairs of the People' s Republic of China, 2020, (4): 113-120.

25 WANG Hongbo, CHENG Feng, ZHANG Zhongfan, et al. Differential characteristics of cultivated land grade and its effect on cultivated land protection in China [J]. Transactions of the CSAE, 2011, 27(11): $1-8$.

26 ZOU Jinlang, YANG Zisheng, WU Qun. Structural feature of cultivated land use output in China. Journal of Natural Resources, 2015, 30(8): 1267-1277.

27 XU Xinliang, WANG Liang, CAI Hongyan, et al . The influences of spatiotemporal change of cultivated land on food crop production potential in China [J]. Food Security, 2017, 9(3): 485-495

28 WANG Shichao, WANG Jinzhou, ZHAO Yawen, et al. Assessment of the contribution percentage of inherent soil productivity of cultivated land in China [J]. Journal of Integrative Agriculture, 2019, 18(11): 2619-2627.

29 GAO Chan, ZHANG Bangbang, ZHAO Minjuan, et al. Grain Productivity potential of cultivated land and yield gap analysis in China $[\mathrm{J}]$. Journal of China Agricultural University, 2020, 25(1): 10-18.

30 YANG Shiqin, YANG Zisheng. Problems and strategies for arable land eco-conservation in China [J]. Agricultural Science \& Technology, 2017, 18(7): 1355-1357+1360.

31 Department of Environmental Protection, Ministry of Land and Resources of the People's Republic of China. Bulletin of the National Survey of Soil Pollution [R]. China Land and Resources Daily, 2014-04-18(2).

32 CHEN Nengchang, ZHENG Yuji, HE Xiaofeng, et al. Analysis of the Report on the national general survey of soil contamination [J]. Journal of AgroEnvironment Science, 2017, 36(9): 1689-1692.

33 DUAN Qiannan, LEE Jianchao, LIU Yansong, et al. Distribution of heavy metal pollution in surface soil samples in China: a graphical review [J]. Bulletin of Environmental Contamination and Toxicology, 2016, 97(3): 303-309.

34 YANG Zisheng, HE Yimei. Soil erosion of cultivated land in mountainous areas at China's southwest Border: a Case Study in Yunnan Province
[J]. Research of Soil and Water Conservation, 2009, 16(1): 1-7.

35 WANG Ping, SHI peijun. Comprehensive regionalization of agricultural natural disaster in China $[\mathrm{J}]$. Journal of Natural Disasters, 2000, 9(4):16-23.

36 YANG Zisheng, LIU Yansui. Study on drought disaster regionalization in China [C]/YANG Zisheng. Research on Water Governance and Sustainable Development of China. Beijing: Social Sciences Academic Press (China), 2012. 169-180.

37 YANG Zisheng, LIU Yansui. Study on flood disaster regionalization in China [C]/YANG Zisheng. Research on Water Governance and Sustainable Development of China. Beijing: Social Sciences Academic Press (China), 2012. 192-201.

38 YANG Zisheng, HE Yimei. Study on grain yield reduction of China due to flood and drought disasters from 1950 to 2010 [C]/YANG Zisheng. Research on Water Governance and Sustainable Development of China. Beijing: Social Sciences Academic Press (China), 2012. 202-213.

39 ZHU Hongbo, ZHANG Anlu. Analysis on spatial-temporal difference in ecological security of cultivated land resources in China [J]. Resources and Environment in the Yangtza Basin, 2007, 16(6): 754754.

40 Wang Qian, Jin Xiaobin, Zhou Yinkang. cultivated land ecological security and spatial aggregation pattern $\mathrm{n}$ in Hebei Province [J]. Transactions of the Chinese Society of Agricultural Engineering, 2011, 27(8): 338-344.

41 ZHANG Rui, LIU Youzhao. Evaluation on cultivated land ecological security based on the PSR model and diagnosis of its obstacle indicators in China $[\mathrm{J}]$. Resources and Environment in the Yangtza Basin, 2013, 22(7): 945-951.

42 KUANG Lihua, YE Yingcong, ZHAO Xiaomin, et al. Evaluation and obstacle factor diagnosis of cultivated land system security in Yingtan City based on the improved TOPSIS Method. Journal of Natural Resources, 2018, 33(9): 1627-1641.

43 LU Hua, XIE Hualin, LV Tiangui, et al. Determinants of cultivated land recuperation in ecologically damaged areas in China [J]. Land Use Policy, 2019, 81: 160-166.

44 LI Hong, ZHI Shuonan. Dynamic Study on China's Energy Security under the New Normal: Based on Gray Correlation TOPSIS Model [J]. Ecological Economy, 2020, 36(8): 57-62+87.

45 XIA Shaowei, YANG JiaBen, YANG Zhenbin. Introduction to Systems Engineering [M]. Beijing: Tsinghua University Press, 1995. 30-210.

46 HU Yonghong. The Improved Method for TOPSIS in Comprehensive Evaluation [J]. Mathematics in Practice and Theory, 2002, 32(4): 572-575. 
47 María Elena Arce, Ángeles Saavedry, José L.Míguez, Enrique Granada. (Arce M E, Saavedra Á, Míguez J L, et al.) The use of grey-based methods in multi-criteria decision analysis for the evaluation of sustainable energy systems: A review [J]. Renewable \& Sustainable Energy Reviews, 2015, 47: 924-932.

48 HE Bowen, LI Ding, LIU Xiaojie. Regional differentiation characteristics and the influencing factors of spatial poverty in rural areas of Gansu Province [J]. Research of Agricultural Modernization, 2019, 40(5): 819-829.

49 ZHOU Lei, HUANG Qiuhao. Efficiency Evaluation on Urban Land Use Based on the Gray Correlation TOPSIS Method and Diagnosis of Its Obstacle Indicators [J]. Research of soil and water conservation, 2014, 21(4): 39-44.

50 ZHOU Honghao, CHEN Xiaohong. Spatiotemporal evolution of sustainable livelihood security and study of its obstacle indicators in northeast China[J]. Scientia Geographica Sinica, 2018, 38(11): 1864-1874.

51 ZHANG Fengrong, Wang Jing, CHEN Baiming, et al. Index System and Evaluation Method of Sustainable Land Use [M]. Beijing: China Agricultural Publishing House, 2003.18-56.

52 CHEN Baiming. Design and evaluation of indicator system of regional land for sustainable use [J]. Progress in Geography, 2002, 21(3): 204-215.

53 Ministry of Natural Resources of the People's Republic of China. Statistical Yearbook of Land and Resources in China [M]. Beijing: Geological Publishing House, 2019. 3-12.

54 Ministry of Water Resources of the People's Republic of China. Water Conservancy Industry Standard of the People's Republic of China: SL 1902007, Standards for classification and gradation of soil erosion [S]. Beijing: China Water Conservancy and hydropower press, 2008. 8-12.

55 General Administration of Quality Supervision, Inspection and Quarantine of the People's Republic of China, Standardization Administration of the People's Republic of China. National Standard of the People's Republic of China: GB/T2438.1-2009, Natural Disaster Information Statistics-Part1: Basic Indicators [S]. Beijing: China Standard Press, 2009. $1-5$. 